\title{
Progressive familial intrahepatic cholestasis type 1
}

INSERM

\section{Source}

INSERM. (1999). Orphanet: an online rare disease and orphan drug data base.

Progressive familial intrahepatic cholestasis type 1. ORPHA:79306

PFIC1, a type of progressive familial intrahepathic cholestasis (PFIC, see this term), is an infantile hereditary disorder in bile formation that is hepatocellular in origin and associated with extrahepatic features. 